\title{
Generating Brain Waves, the Power of Astrocytes
}

\author{
Yossi Buskila1,2*, Alba Bellot-Saez ${ }^{1,2}$ and John W. Morley ${ }^{1}$ \\ ${ }^{1}$ School of Medicine, Western Sydney University, Campbelltown, NSW, Australia, ${ }^{2}$ International Centre for Neuromorphic \\ Systems, The MARCS Institute, Western Sydney University, Penrith, NSW, Australia
}

\section{OPEN ACCESS}

Edited by:

Yuki Hayashida,

Osaka University, Japan

Reviewed by:

Jit Muthuswamy,

Arizona State University, United States

Alexei Verkhratsky,

University of Manchester,

United Kingdom

*Correspondence:

Yossi Buskila

Y.buskila@westernsydney.edu.au;

buskila63@gmail.com

Specialty section: This article was submitted to

Neural Technology,

a section of the journal

Frontiers in Neuroscience

Received: 30 July 2019 Accepted: 04 October 2019

Published: 18 October 2019

Citation:

Buskila Y, Bellot-Saez A and Morley JW (2019) Generating Brain

Waves, the Power of Astrocytes.

Front. Neurosci. 13:1125.

doi: 10.3389/fnins.2019.01125
Synchronization of neuronal activity in the brain underlies the emergence of neuronal oscillations termed "brain waves", which serve various physiological functions and correlate with different behavioral states. It has been postulated that at least ten distinct mechanisms are involved in the formulation of these brain waves, including variations in the concentration of extracellular neurotransmitters and ions, as well as changes in cellular excitability. In this mini review we highlight the contribution of astrocytes, a subtype of glia, in the formation and modulation of brain waves mainly due to their close association with synapses that allows their bidirectional interaction with neurons, and their syncytium-like activity via gap junctions that facilitate communication to distal brain regions through $\mathrm{Ca}^{2+}$ waves. These capabilities allow astrocytes to regulate neuronal excitability via glutamate uptake, gliotransmission and tight control of the extracellular $\mathrm{K}^{+}$ levels via a process termed $\mathrm{K}^{+}$clearance. Spatio-temporal synchrony of activity across neuronal and astrocytic networks, both locally and distributed across cortical regions, underpins brain states and thereby behavioral states, and it is becoming apparent that astrocytes play an important role in the development and maintenance of neural activity underlying these complex behavioral states.

Keywords: brain waves, oscillations, astrocytes, spatial buffering, $\mathrm{K}^{+}$clearance

\section{INTRODUCTION}

\section{Neuronal Oscillations}

In the central nervous system (CNS), neurons communicate via electrochemical signals which leads to flow of ionic currents through synaptic contacts (Schaul, 1998). At the network level, the synchronization of the neuron's electrical activity gives rise to rhythmic voltage fluctuations traveling across brain regions, known as neuronal oscillations or brain waves (Buzsaki, 2006).

Neuronal oscillations can be modulated in space and time and are affected by the dynamic interplay between neuronal connectivity patterns, cellular membrane properties, intrinsic circuitry, speed of axonal conduction and synaptic delays (Nunez, 1995; Sanchez-Vives and McCormick, 2000; Cunningham et al., 2006; Buskila et al., 2013; Tapson et al., 2013). At the cellular level, these synchronous oscillations fluctuate between two main states, known as "up states" and 
"down states", which occur in the neocortex both in vitro and in vivo (Sanchez-Vives and McCormick, 2000). Whereas Down states refer to resting activity and membrane hyperpolarization, Up states are associated with neuronal depolarization and firing bursts of action potentials (Cossart et al., 2003). Importantly, Up states occurring within spatially organized cortical ensembles have been postulated to interact with each other to produce a temporal window for neuronal network communication and coordination (Fries, 2005). This network coherence was found to be essential for several sensory and motor processes, as well as for cognitive flexibility (i.e., attention, memory), thereby playing a fundamental role in the brain's basic functions (Fries et al., 2001; Tallon-Baudry et al., 2004).

Emerging technologies during the past decades led to the description of multiple neuronal oscillations displaying different electrophysiological and connectivity properties across brain areas including the neocortex, thalamus and hippocampus (Steriade, 2006). Using power spectrum analysis, investigators identified that neuronal oscillations fluctuate within specific frequency bands, ranging from very slow $(<0.01 \mathrm{~Hz})$ to ultra-fast $(>1,000 \mathrm{~Hz})$ oscillations, mediated by at least ten different mechanisms (Penttonen and Buzsáki, 2003). Whereas fast oscillators are found to be more localized within a restricted neural volume (Contreras and Llinas, 2001), slow oscillations typically involve large synchronous membrane voltage fluctuations in wider areas of the brain (He et al., 2008). These network dynamics and connectivity patterns can change according to the behavioral state, with some frequency bands being associated with sleep, while other frequencies predominate during arousal or conscious states (Brooks, 1968; Achermann and Borbély, 1997; Murthy and Fetz, 2006) (Table 1). Interestingly, neuronal oscillations interact across different frequency bands to modulate each other and engage specific behaviors (Buzsaki, 2006; Steriade, 2006), and previous studies have postulated that different oscillation frequencies either compete with each other or cooperate in a specific manner to participate in distinct physiological processes such as bias of input selection, temporal linkage of neurons into assemblies and facilitation of synaptic plasticity (Buzsáki and Draguhn, 2004; Isomura et al., 2006). Moreover, oscillation phase relationships between regions are diverse and can be modulated by sensory and motor experiences (Maris et al., 2016), thereby adding greater complexity in deciphering how brain waves coordinate to subserve important functions in both the developing and adult human brain.

The common view of oscillatory frequency bands is that they represent groups of neuronal oscillations acting as distinct entities that work similarly during particular brain functions (Watson, 2015), and therefore, can serve as a fundamental tool for both clinical diagnosis and brain research (Huber et al., 2004; Buzsaki, 2006). In addition, the fact that brain waves expressed in many species (e.g., human, macaque, cat, rabbit, rat) and their behavioral correlates are preserved throughout evolution is a testament to their fundamental role in mediating synchronization across neuronal ensembles to efficiently coordinate and propagate neuronal signals at the network level (Hughes et al., 2004;
Bereshpolova et al., 2007; Skaggs et al., 2007; Nir et al., 2011; Peyrache et al., 2011).

\section{Mechanisms Underpinning Neuronal Oscillations}

Neuronal oscillations show a linear progression on a natural logarithmic scale with little overlap (Penttonen and Buzsáki, 2003), leading to the suggestion that at least ten distinct and independent mechanisms are required to cover the large frequency range of brain waves, and it has been reported that several oscillations are driven by multiple mechanisms (Buzsáki and Draguhn, 2004; Buzsaki, 2006). Some of the suggested mechanisms underlying the generation of network oscillations are summarized in Table $\mathbf{1}$, and most of them include reciprocal interactions between excitatory and inhibitory mechanisms (Singer, 1993) or changes in cellular excitability (Liljenström and Hasselmo, 1993; Ainsworth et al., 2011; Bellot-Saez et al., 2018). The latter is often associated with alterations in extracellular ions (e.g., $\mathrm{K}^{+} ; \mathrm{Ca}^{2+}$ ) and the hyperpolarization-activated inward current $\left(I_{h}\right)$ (Steriade et al., 1993), which can regulate intrinsic membrane properties such as the resonance frequency (Tohidi and Nadim, 2009; Bellot-Saez et al., 2018), as well as the strength and frequency of network oscillations (Yue and Huguenard, 2001). In this mini-review we will focus on mechanisms by which astrocytes effect neuronal excitability.

Neurons consist of inherent membrane resonance and frequency preference properties (Hutcheon and Yarom, 2000; Buskila et al., 2013) that allow them to act as resonators or transient oscillators that amplify inputs within certain frequencies (Alonso and Llinás, 1989). This oscillatory behavior at multiple frequencies depends on the accurate combination of both low-pass (i.e., passive leak conductance, membrane capacitance) and high-pass (i.e., voltage-gated channels activated close to the resting membrane potential, RMP) filtering properties (Buzsaki, 2006), which endow neurons with a wide repertoire to respond faster and more efficiently to spike trains or fast inputs (Pike et al., 2000). Therefore, alterations in membrane conductance or excitability along the somatodendritic compartments result in differential tuning of the resonant response in different cell types (e.g., interneurons vs. pyramidal or cholinergic cells), which on the one hand filter inputs from neurons that are not synchronized [see Hutcheon and Yarom (2000) and Laudanski et al. (2014) for comprehensive review], and on the other hand is essential for the synchronization of neurons that express similar resonance, therefore, sculpting the functionality of a neuronal network (Hutcheon and Yarom, 2000; Whittington and Traub, 2003; Laudanski et al., 2014; Kékesi et al., 2019).

Consequently, changes in the concentration of extracellular ions that impact the excitability and resonance behavior of individual neurons (e.g., $\mathrm{K}^{+}, \mathrm{Mg}^{2+}, \mathrm{Ca}^{2+}$ ), can affect brain rhythms. Indeed, a recent comprehensive report from Nedergaard's group, in which they have recorded different brain rhythms during the sleep-awake cycle show that different rhythms are linked with alterations in extracellular concentrations of $\mathrm{K}^{+}, \mathrm{Ca}^{2+}, \mathrm{Mg}^{2+}$, and $\mathrm{H}^{+}$(Ding et al., 2016), 
TABLE 1 | Common characteristics of brain waves.

\begin{tabular}{|c|c|c|c|c|c|c|c|c|c|}
\hline Band & \multicolumn{2}{|r|}{ Delta - $\delta$} & \multicolumn{2}{|r|}{ Theta $-\theta$} & \multicolumn{2}{|r|}{ Alpha $-\alpha$} & Beta - $\beta$ & \multicolumn{2}{|r|}{ Gamma - $\gamma$} \\
\hline Frequency & & $1-4 \mathrm{~Hz}$ & & 4-10 Hz & & $8-12 \mathrm{~Hz}$ & $12-30 \mathrm{~Hz}$ & & $>30 \mathrm{~Hz}$ \\
\hline EEG traces & & & & 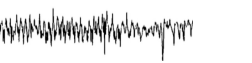 & & 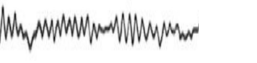 & 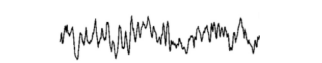 & & 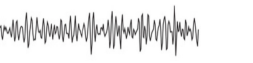 \\
\hline Brain area & & $\begin{array}{l}\text { Dcortex, Thalamus, } \\
\text { Basal ganglia }\end{array}$ & $\begin{array}{l}\text { Hipp } \\
\text { gyrus }\end{array}$ & $\begin{array}{l}\text { ocampus, Dentate } \\
\text {, Cortex, Amygdala }\end{array}$ & $\mathrm{Neo}$ & ocortex, Thalamus & $\begin{array}{c}\text { Neocortex, Olfactory bulb, } \\
\text { Striatum, Thalamus } \\
\text { Hippocampus }\end{array}$ & Neocc & $\begin{array}{l}\text { Hippox, Olfactory bulb, } \\
\text { Hippocampus }\end{array}$ \\
\hline $\begin{array}{l}\text { Brain } \\
\text { functions }\end{array}$ & $\begin{array}{l}\text { (a) } \\
\text { (b) } \\
\text { (c) } \\
\text { (d) } \\
\text { (e) }\end{array}$ & $\begin{array}{l}\text { Slow wave sleep and } \\
\text { deep NREM sleep } \\
\text { Signal detection and } \\
\text { decision making } \\
\text { Memory consolidation } \\
\text { Concentration, } \\
\text { motivation and } \\
\text { focused attention } \\
\text { Facilitation of } \\
\text { interlaminar } \\
\text { interactions in the } \\
\text { cortex to control } \\
\text { synaptic rescaling }\end{array}$ & $\begin{array}{l}\text { (a) } \\
\text { (b) } \\
\text { (c) } \\
\text { (d) }\end{array}$ & $\begin{array}{l}\text { REM sleep } \\
\text { Selective attention, } \\
\text { arousal, orienting, and } \\
\text { voluntary control of } \\
\text { movement } \\
\text { Modulation of } \\
\text { synaptic strength and } \\
\text { coordination of phase } \\
\text { coding of active } \\
\text { neuronal ensembles } \\
\text { Episodic memory, } \\
\text { word integration and } \\
\text { environmental } \\
\text { encoding }\end{array}$ & $\begin{array}{l}\text { (a) } \\
\text { (b) } \\
\text { (c) }\end{array}$ & $\begin{array}{l}\text { Drowsiness and } \\
\text { relaxation } \\
\text { Sensory function, } \\
\text { movement and visual } \\
\text { perceptual framing } \\
\text { Task engagement, } \\
\text { speed of working } \\
\text { memory and cognitive } \\
\text { performance }\end{array}$ & $\begin{array}{l}\text { (a) Sensorimotor control, } \\
\text { motor preparation. } \\
\text { (b) Sensory processing- } \\
\text { amplification of } \\
\text { olfactory and visual } \\
\text { stimuli } \\
\text { (c) Top-down attention } \\
\text { and working memory } \\
\text { allocation }\end{array}$ & $\begin{array}{l}\text { (a) } \\
\text { (b) } \\
\text { (c) }\end{array}$ & $\begin{array}{l}\text { Focused attention } \\
\text { and motor task } \\
\text { execution } \\
\text { Responses to evoked } \\
\text { auditory and visual } \\
\text { stimuli } \\
\text { Facilitation of neuronal } \\
\text { communication and } \\
\text { efficient cognitive } \\
\text { processing } \\
\text { Spatial working and } \\
\text { recognition memory }\end{array}$ \\
\hline $\begin{array}{l}\text { Rhythm } \\
\text { generators }\end{array}$ & $\begin{array}{l}\text { (1) } \\
\text { (2) } \\
\text { (3) }\end{array}$ & $\begin{array}{l}\text { Interplay between low } \\
\text { threshold } \mathrm{Ca}^{2+} \\
\text { transient current and } \\
\text { hyperpolarization } \\
\text { activated cation } \\
\text { current (McCormick } \\
\text { and Pape, 1990; } \\
\text { Soltesz et al., 1991) } \\
\text { NMDAR-driven } \\
\text { depolarization of } \\
\text { intrinsically bursting } \\
\text { neurons (Connors } \\
\text { et al., 1982; } \\
\text { Carracedo et al., } \\
\text { 2013; Steriade et al., } \\
\text { 2018) } \\
\text { Neuron-glia } \\
\text { interactions to } \\
\text { regulate extracellular } \\
\text { K}^{+} \text {through Ca }{ }^{2+} \\
\text { waves (Amzica et al., } \\
\text { 1997, 2002; } \\
\text { Kozachkov and } \\
\text { Michmizos, 2017) }\end{array}$ & $\begin{array}{l}\text { (1) } \\
\text { (2) } \\
\text { (3) } \\
\text { (4) } \\
\text { (4) } \\
\end{array}$ & $\begin{array}{l}\text { Interplay between } \\
\text { inhibitory and } \\
\text { excitatory } \\
\text { hippocampal neurons } \\
\text { that is modulated by } \\
\text { cholinergic and } \\
\text { GABAergic input from } \\
\text { the medial septum } \\
\text { (Freund and Antal, } \\
\text { 1988; Buzsáki, 2002; } \\
\text { Hangya et al., 2009) } \\
\text { Interplay between } \\
\text { slow inward K+ } \\
\text { currents and } \\
\text { persistent Na+ } \\
\text { current (D'Angelo } \\
\text { et al., 2001) } \\
\text { ACh-mediated Ca }{ }^{2+} \\
\text { release from } \\
\text { astrocytic internal } \\
\text { stores (Foley et al., } \\
2017 \text { ) } \\
\text { Neuromodulation of } \\
\text { the prefrontal cortex } \\
\text { by Dopamine (Eckart } \\
\text { et al., 2016) }\end{array}$ & $\begin{array}{l}\text { (1) } \\
\text { (2) } \\
\text { (3) } \\
\text { (3) }\end{array}$ & $\begin{array}{l}\text { Cholinergic } \\
\text { modulation of the } \\
\text { prefrontal cortex } \\
\text { (Dipoppa and Gutkin, } \\
\text { 2013) } \\
\text { Activation of mGluR1 } \\
\text { in the GJ connected } \\
\text { high-threshold } \\
\text { bursting neurons in } \\
\text { the lateral geniculate } \\
\text { nucleus (Hughes } \\
\text { et al., 2004, 2011) } \\
\text { Activation of the } \\
\text { noradrenergic } \\
\text { neurons in the locus } \\
\text { ceruleus, mediated by } \\
\text { Corticotropin } \\
\text { releasing hormone } \\
\text { (McCormick, 1992; } \\
\text { Jedema, 2004; Enoch } \\
\text { et al., 2008) }\end{array}$ & $\begin{array}{l}\text { (1) Activation of gap } \\
\text { junction-coupled layer } \\
\text { V neurons, mediated } \\
\text { by the M-type } \mathrm{K}^{+} \\
\text {current (Roopun } \\
\text { et al., 2006) } \\
\text { (2) ACh modulation of } \\
\text { synaptic interactions } \\
\text { between layer } \mathrm{V} \\
\text { pyramidal neurons } \\
\text { and low-threshold } \\
\text { spiking interneurons } \\
\text { (Roopun et al., 2010) }\end{array}$ & $\begin{array}{l}\text { (3) } \\
\text { (4) }\end{array}$ & $\begin{array}{l}\text { Tonic activation of } \\
\text { interneurons by } \\
\text { mGluR (Whittington } \\
\text { et al., 1995) } \\
\text { Cholinergic } \\
\text { modulation of } \\
\text { pyramidal neurons } \\
\text { (Fisahn et al., 1998) } \\
\text { Modulation of } \\
\text { interneurons via gap } \\
\text { junctions; activation of } \\
\text { inhibitory interlaminar } \\
\text { connections } \\
\text { (Ainsworth et al., } \\
\text { 2011) } \\
\text { Ca }{ }^{2+} \text { - dependent } \\
\text { glutamate release } \\
\text { from astrocytes (Lee } \\
\text { et al., 2014) } \\
\text { Increase in [K+ } \text { I }_{0} \\
\text { enhance activation of } \\
\text { fast inhibitory and } \\
\text { excitatory networks } \\
\text { (Traub et al., 2001; } \\
\text { LeBeau et al., 2002) }\end{array}$ \\
\hline
\end{tabular}

confirming that cellular mechanisms which particularly affect the ionic composition of the extracellular fluid can modulate the excitability and synchronous activity of neurons, thus affecting the different brain rhythms. Accordingly, $\mathrm{K}^{+}$channels which mediate $\mathrm{K}^{+}$efflux and membrane repolarization, play a crucial role in determining the overall network excitability and have been suggested to affect the generation of neuronal oscillations at multiple frequencies (Buzsaki, 2006). Consistent with this view, D’Angelo et al. (2001) showed via experimental and computational modeling of cerebellar granule cells that slow repolarizing $\mathrm{K}^{+}$currents terminate the oscillatory "up state" of theta oscillations amplified by a persistent $\mathrm{Na}^{+}$current and therefore, underlie the bursting and resonant behavior of theta oscillations. In line with these results, activation of $\mathrm{K}^{+}$currents has been associated with enhanced spike timing precision at gamma frequencies in both pyramidal and basket cells in the hippocampus (Penttonen et al., 1998), as well as with lower frequency oscillations in the delta range (Ushimaru et al., 2012). Moreover, intracellular recordings of cortical neurons during alterations in $\mathrm{K}^{+}$homeostasis indicate changes in neuronal excitability and resonance behavior that affected the amplification of network oscillations (Bellot-Saez et al., 2018).

$\mathrm{K}^{+}$homeostasis in the brain is governed by the activity of astrocytes through several mechanisms, including $\mathrm{K}^{+}$clearance from the extracellular fluid. Astrocytes are strategically located 
close to synapses, which allows them to critically regulate the overall network function (Wang et al., 2012; Bellot-Saez et al., 2017). Two major mechanisms of astrocytic $\mathrm{K}^{+}$clearance have been established: (i) net $\mathrm{K}^{+}$uptake, in which the excess of extracellular $\mathrm{K}^{+}\left(\left[\mathrm{K}^{+}\right]_{o}\right)$ is taken up by $\mathrm{K}^{+}$cotransporters $\left(\mathrm{Na}^{+} / \mathrm{K}^{+} / 2 \mathrm{Cl}^{-}\right), \mathrm{Na}^{+} / \mathrm{K}^{+}$pumps $\left(\mathrm{Na}^{+} / \mathrm{K}^{+}\right.$ATPase), and inward rectifying $\mathrm{K}^{+}$channels $\left(\mathrm{K}^{+}{ }_{i r}\right)$ that are expressed in astrocytic processes and (ii) $\mathrm{K}^{+}$spatial buffering, in which $\mathrm{K}^{+}$ions propagate from high to low concentrations through gapjunction (GJ) mediated astrocytic networks by employing membrane voltage differences between the local $\mathrm{K}^{+}$reversal potential to the astrocytic network membrane potential, and then released in distal regions of the astrocytic networks (Figure 1). Ultimately, the $\left[\mathrm{K}^{+}\right]_{o}$ is returned to baseline levels to prevent hyperexcitability (Verkhratsky and Nedergaard, 2018). Consistent with the importance of the $\mathrm{K}^{+}$clearance to normal oscillatory functioning, genetically modified mice that suffer from impaired clearance mechanisms exhibit epileptic seizures, growth retardation, and premature lethality at the age of 2 weeks (Kofuji et al., 2000; Bellot-Saez et al., 2017; Do-Ha et al., 2018). However, recent reports indicate that under physiological conditions, neuromodulators can directly trigger an increase in $\left[\mathrm{K}^{+}\right]_{o}$ and thus signal through astrocytes to alter neural circuit activity and regulate network oscillations (Ding et al., 2016; Ma et al., 2016).

\section{Astrocytic Modulation of Brain Waves}

Numerous studies revealed the essential contributions made by astrocytes to many physiological brain functions, including synaptogenesis (Ullian et al., 2001), metabolic coupling (Magistretti, 2006), nitrosative regulation of synaptic release (Buskila et al., 2005; Abu-Ghanem et al., 2008; Buskila and Amitai, 2010), synaptic transmission (Fields and Stevens-Graham, 2002), network oscillations (Bellot-Saez et al., 2018), and plasticity (Suzuki et al., 2011; Oberheim et al., 2012).

Astrocytes express a plethora of receptors, ion channels, pumps (i.e., ATPase) and cotransporters allowing them to dynamically interact with neurons through several pathways (Haydon and Carmignoto, 2006; Giaume and Theis, 2010; Larsen and Macaulay, 2014). Despite lacking the ability to fire action potentials, astrocytes communicate with neurons and other astrocytes mainly via $\mathrm{Ca}^{2+}$ signals (Cornell-Bell et al., 1990; Shigetomi et al., 2010). Astrocytic $\mathrm{Ca}^{2+}$ signals can occur both independently of neuronal activity or following neurotransmitter release and include intrinsic $\mathrm{Ca}^{2+}$ oscillations within individual cells and $\mathrm{Ca}^{2+}$ waves that propagate from one astrocyte to another (Zur Nieden and Deitmer, 2006; Nett et al., 2017). Indeed, recent studies found that astrocytic $\mathrm{Ca}^{2+}$ signaling and glutamate clearance by astrocytes play an essential role in the regulation of the network activity and $\mathrm{K}^{+}$homeostasis, which ultimately affects the neuronal excitability underlying network oscillations (Wang et al., 2012; Ding et al., 2016). Recently, Ma et al. (2016) showed that neuromodulators can signal through astrocytes by affecting their $\mathrm{Ca}^{2+}$ oscillations to alter neuronal circuitry and consequently behavioral output. In line with these observations, Nedergaard's group further demonstrated that bath application of neuromodulators to cortical brain slices increased $\left[\mathrm{K}^{+}\right]_{o}$ regardless of synaptic activity (Ding et al., 2016), suggesting that increased $\left[\mathrm{K}^{+}\right]_{o}$ could serve as a mechanism to maximize the impact of neuromodulators on the synchronous activity of neurons and their recruitment into networks.

Interestingly, an in vivo study found that spontaneous $\mathrm{Ca}^{2+}$ oscillations in astrocytes differ between cortical layers, suggesting functional network segregation imposed by astrocytic function (Takata and Hirase, 2008). Indeed, the spatial and functional organization of astrocytes varies between different brain regions (Houades et al., 2008; Chai et al., 2017; Matias et al., 2019) establishing that astrocytes are organized into anatomical and functional compartments (Pannasch and Rouach, 2013). Similarly, a computational model of three-dimensional astrocytic networks showed that the propagation of astrocytic $\mathrm{Ca}^{2+}$ waves is highly variable between brain regions depending on their GJcoupling organization within the astrocytic network, with short-distance connections favoring spreading of $\mathrm{Ca}^{2+}$ waves over wider areas (Lallouette et al., 2014). In addition, several studies have provided evidence that astrocytes respond to different neuronally released neurotransmitters and neuromodulators (e.g., Acetylcholine, 5-HT, Histamine, Norepinephrine, Dopamine) by eliciting $\mathrm{Ca}^{2+}$ elevations that trigger signaling cascades leading to alterations in the concentrations of intracellular and extracellular ions (e.g., $\mathrm{Na}^{+}$, $\mathrm{Ca}^{2+}, \mathrm{K}^{+}$) and gliotransmitter release (Blomstrand et al., 1999; Jung et al., 2000; Oikawa et al., 2005; Ding et al., 2013; Jennings et al., 2017; Covelo and Araque, 2018). These studies emphasize the bidirectional communication pathway between neurons and astrocytes, which establish a synergetic mechanism to affect network oscillations.

Recently, Mariotti et al. (2016, 2018) demonstrated that astrocytic modulation and signaling are circuit-specific, as cortical astrocytes not only respond to excitatory inputs, but also react to inhibitory interneurons by eliciting weak or strong $\left[\mathrm{Ca}^{2+}\right]_{i}$ elevations. In addition, two-photon imaging experiments revealed that cortical astrocytes are fast enough to respond to sensory stimulation by evoking fast $\mathrm{Ca}^{2+}$ events (Stobart et al., 2018). Together, these studies suggest that astrocytes are able to process different patterns of network activity with a variety of $\mathrm{Ca}^{2+}$ signals in order to decode and integrate local synaptic activity and plasticity (Perea and Araque, 2007; Henneberger et al., 2010; Navarrete et al., 2012), as well as other physiological processes including vasodilation through nitric oxide (Buskila and Amitai, 2010; Muñoz et al., 2015), $\mathrm{K}^{+}$signaling (Filosa et al., 2006), release of trophic factors (Igelhorst et al., 2015), and inflammatory mediators (Michelucci et al., 2016). Moreover, gliotransmitters can activate neuronal receptors, including extrasynaptic NR1/NR2B-containing NMDA receptors (Fellin et al., 2004; Jourdain et al., 2007; Wang et al., 2013), thereby establishing reciprocal interactions between neurons and astrocytes that result in the overall modulation of the network excitability and synchronous activity of groups of neurons (Sardinha et al., 2017; Adamsky et al., 2018). 


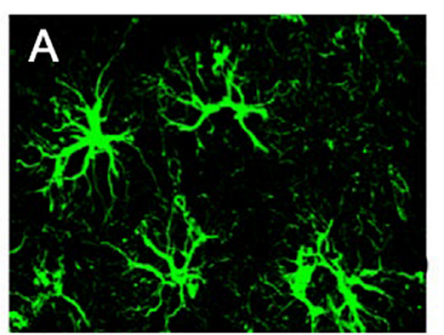

$\mathrm{K}^{+}$spatial buffering

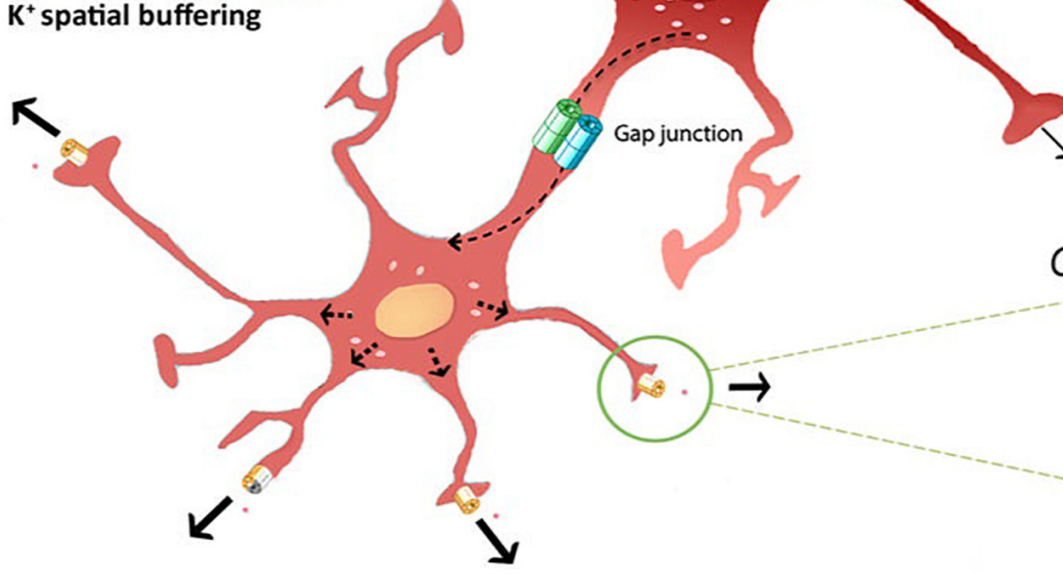

\section{$\int$ Pyramidal neuron} Astrocyte

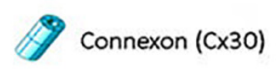

99 Kir2.1

89 Kir5.1

99 Kir4.1 Na'ions

Connexon (Cx43) ONKCC

M $\mathrm{Na}^{*} / \mathrm{K}^{*}$ ATPase $\mathrm{K}^{*}$ ions $\bullet \mathrm{Cl}^{-}$ions

\section{$\mathrm{K}^{+}$uptake Tripartite synapse}

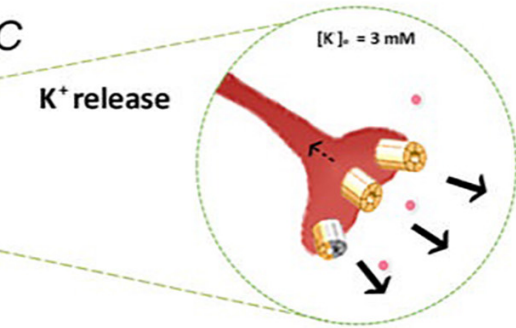

$\mathrm{Vk}<\mathrm{Vm}$

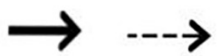

Electrodifusive Forces

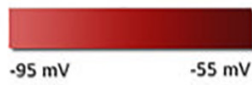

C

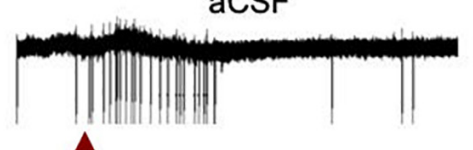

D

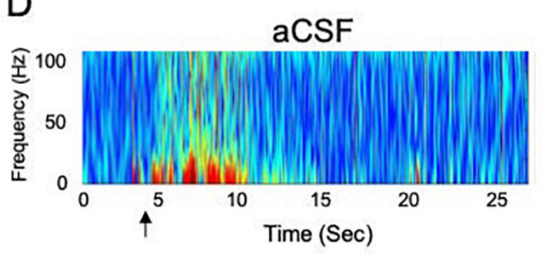

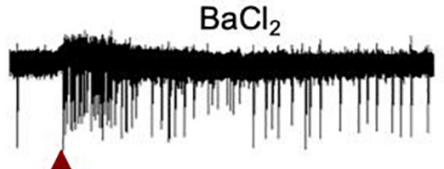

$\mathrm{BaCl}_{2}$

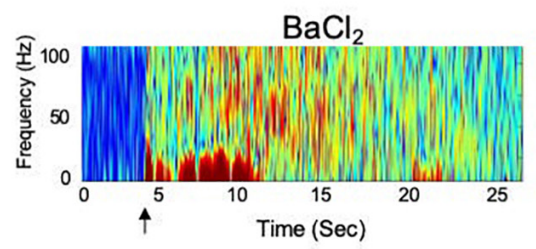

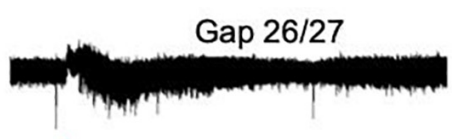

$\Delta$

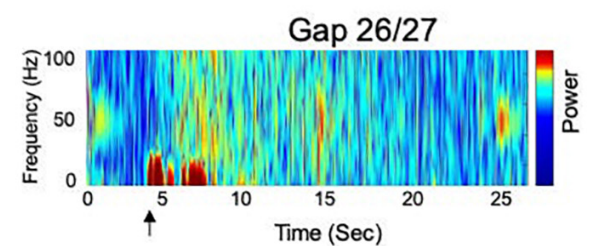

FIGURE 1 | The impact of astrocytic $\mathrm{K}^{+}$clearance on network oscillations. (A) Image of GFP labeled cortical astrocytes depicting their organization in non-overlapping domains. (B) Schematic diagram describing the mechanisms of astrocytic $\mathrm{K}^{+}$clearance. Top-right inset $-\mathrm{K}^{+}$uptake- local increase of $\left[\mathrm{K}^{+}\right]_{0}$ is cleared from the extracellular space through the astrocytic Kir channels, NKCC and $\mathrm{Na}^{+} / \mathrm{K}^{+}$ATPase. Eventually, $\mathrm{K}^{+}$ions flow intracellularly through GJ-connected astrocytes ( $\mathrm{K}^{+}$spatial buffering) and promote a distal outward current to the extracellular space, where $\left[\mathrm{K}^{+}\right]_{0}$ is low $(\sim 3 \mathrm{mM})$ as shown in the lower inset $\left(\mathrm{K}^{+}\right.$ release). Arrows indicate the direction of $\mathrm{K}^{+}$driving force. (C) The functional role of astrocytic $\mathrm{K}^{+}$clearance processes on network oscillations. Traces of extracellular recordings showing the network activity before and after brief (1 s) application of $30 \mathrm{mM} \mathrm{KCl}$ (red arrow), in normal aCSF (left) and after bath application of $100 \mu \mathrm{M}$ $\mathrm{BaCl}_{2}$ (selective blocker of astrocytic Kir4.1 channels, middle trace) or Gap-26/27 (selective blocker of Cx43, right). Note the increase in network excitability following the increase in $\left[\mathrm{K}^{+}\right]_{0}$ depicted as increase in spiking activity. (D) Color coded spectrogram of network oscillations depicting the network activity before and after local increase in $\left[\mathrm{K}^{+}\right]_{0}$ (black arrows, imitating high local neuronal activity) under normal conditions (aCSF, left), following impairment in $\mathrm{K}^{+}$uptake with $100 \mu \mathrm{M}$ BaCl 2 (middle spectrogram) or following blockade of astrocytic spatial buffering with selective astrocytic gap-junction blockers (GAP-26/27, right). Adapted from Neuroscience and Biobehavioral Reviews, vol 77, Alba Bellot-Saez, Orsolya Kékesi, John W. Morley, and Yossi Buskila, Astrocytic modulation of neuronal excitability through $\mathrm{K}^{+}$spatial buffering, 87-97, copyright (2017), with permission from Elsevier Ltd., under CC BY license (http://creativecommons.org/licenses/by/4.0/). 
Astrocytes mediate long distance communication not only via $\mathrm{Ca}^{2+}$ waves but also through ATP release (Haas et al., 2006; Suadicani, 2006), which is followed by its degradation to adenosine by extracellular nucleotidases, leading to synaptic inhibition of neurotransmission (Pascual et al., 2005). Consistently, ATP release from neocortical astrocytes has been found to activate purinergic currents in pyramidal neurons, followed by attenuation of synaptic and tonic inhibition (Lalo et al., 2014). These results suggest that cortical astrocytes, via exocytosis of ATP, could also play a role in the modulation of neuronal GABA release and thus phasic and tonic inhibition, which eventually contribute to the generation of hypersynchronous oscillations at the network level.

\section{DISCUSSION}

In the 19th century, Carl Ludwig Schleich was first to propose that neuroglia is the anatomical locus for controlling neuronal excitation and its transmission from neuron to neuron (Schleich, 1894; Dierig, 1994). A year later, Ramón y Cajal, the father of modern neuroscience, proposed that astrocytes are directly involved in modulating neuronal activity by isolating neighboring neurons (Cajal, 1895; Navarrete and Araque, 2014). In support of this view, Cajal further revealed that "the neuroglia is abundant where intercellular connections are numerous and complicated, not due to the existence of contacts, but rather to regulate and control them, in such a manner that each protoplasmic expansion is in an intimate relationship with only a particular group of nerve terminal branches", which led him to propose that astrocytes exert a major role in modulating brain function during different behavioral states (Cajal, 1895, 1897). More than a century later, with the development of powerful electrophysiological and imaging tools (Berger et al., 2007; Pál et al., 2015), these initial insights about astrocytes as potential modulators of the brain circuitry are gaining more support.

The close association of astrocytes with synapses led to the concept of the tripartite synapse, (consisting the pre-synaptic terminal, the post-synaptic membrane and the cradling astrocyte) which allows the bidirectional interaction of astrocytes with neurons (Araque et al., 1999). Although the molecular and cellular pathways in which astrocytes affect neuronal network activity and brain rhythms are not fully clear, numerous in vivo and in vitro studies indicate that they are playing a key role in the modulation of neuronal excitability and network synchronous

\section{REFERENCES}

Abu-Ghanem, Y., Cohen, H., Buskila, Y., Grauer, E., and Amitai, Y. (2008). Enhanced stress reactivity in nitric oxide synthase type 2 mutant mice: findings in support of astrocytic nitrosative modulation of behavior. Neuroscience 156, 257-265. doi: 10.1016/j.neuroscience.2008.07.043

Achermann, P., and Borbély, A. A. (1997). Low-frequency ( $<1 \mathrm{hz})$ oscillations in the human sleep electroencephalogram. Neuroscience 81, 213-222. doi: 10.1016/S0306-4522(97)00186-183

Adamsky, A., Kol, A., Kreisel, T., Doron, A., Ozeri-Engelhard, N., Melcer, T., et al. (2018). Astrocytic activation generates de novo neuronal potentiation and memory enhancement. Cell 174:59-71.e14. doi: 10.1016/j.cell.2018.05.002 activity, thereby contribute to the "conversation in the brain" (Verkhratsky and Nedergaard, 2018).

The fact that astrocytes can regulate the activity of individual neurons prompted a new concept of network modulation termed "lateral astrocyte synaptic regulation" (Covelo and Araque, 2016). Accordingly, astrocytic regulation of synaptic transmission is heterosynaptic and not restricted to the active synapse itself, but involving the activity of distant tripartite synapses via paracrine signaling of gliotransmitters that depends on the morphological and functional properties of astrocytes, thereby acting as a syncytium that can influence neuronal properties over wide brain regions (Pirttimaki et al., 2017). However, the physiological role of gliotransmission is highly debatable (see Nedergaard and Verkhratsky, 2012; Chai et al., 2017; Papouin et al., 2017; Fiacco and McCarthy, 2018; Savtchouk and Volterra, 2018), as gliotransmitter release has been reliably demonstrated only in vitro in cultures and brain slice experiments that are often accompanied by manipulations (e.g., high frequency stimulation) which can affect astrocytic channels or receptors leading to impaired signaling cascades. This experimental design imposes questions about the existence of gliotransmission (Wolosker et al., 2016; Chai et al., 2017) and whether it plays a physiological role in the brain (Fiacco and McCarthy, 2018). Although previous studies found no correlation between astrocytic $\mathrm{Ca}^{2+}$ signaling and gliotransmitter release (Fiacco et al., 2007; Petravicz et al., 2008; Agulhon et al., 2010), there is increasing evidence supporting the importance of both the GJ-mediated connectivity and function of astrocytic networks for neuronal-astrocytic communication and control of neuronal network activity (Covelo and Araque, 2016, 2018). Consequently, astrocytic alterations likely lead to aberrant modulation of both synaptic transmission and synchronization of network oscillations, which is also accompanied by changes in behavioral performance.

\section{AUTHOR CONTRIBUTIONS}

All authors conceived the project, wrote and approved the manuscript.

\section{ACKNOWLEDGMENTS}

This study was supported by IPRA to AB-S and the Ainsworth medical research innovation fund awarded to YB and JM.

Agulhon, C., Fiacco, T. A., and McCarthy, K. D. (2010). Hippocampal short- and long-term plasticity are not modulated by astrocyte Ca2+ signaling. Science 327, 1250-1254. doi: 10.1126/science.1184821

Ainsworth, M., Lee, S., Cunningham, M. O., Roopun, A. K., Traub, R. D., Kopell, N. J., et al. (2011). Dual gamma rhythm generators control interlaminar synchrony in auditory cortex. J. Neurosci. 31, 17040-17051. doi: 10.1523/ jneurosci.2209-11.2011

Alonso, A., and Llinás, R. R. (1989). Subthreshold Na+-dependent theta-like rhythmicity in stellate cells of entorhinal cortex layer II. Nature 342, 175-177. doi: $10.1038 / 342175 \mathrm{a} 0$

Amzica, F., Massimini, M., and Manfridi, A. (2002). Spatial buffering during slow and paroxysmal sleep oscillations in cortical networks of glial cells 
in vivo. J. Neurosci. 22, 1042-1053. doi: 10.1523/jneurosci.22-03-01042. 2002

Amzica, F., Neckelmann, D., and Steriade, M. (1997). Cortical neuron-glia interactions during spike-and-wave (SW) seizures. Soc. Neurosci. Abstr. 23:1688.

Araque, A., Parpura, V., Sanzgiri, R. P., and Haydon, P. G. (1999). Tripartite synapses: glia, the unacknowledged partner. Trends Neurosci. 22, 208-215. doi: 10.1016/S0166-2236(98)01349-1346

Bellot-Saez, A., Cohen, G., van Schaik, A., Ooi, L., Morley, J. W., and Buskila, Y. (2018). Astrocytic modulation of cortical oscillations. Sci. Rep. 8:11565. doi: 10.1038/s41598-018-30003-w

Bellot-Saez, A., Kékesi, O., Morley, J. W., and Buskila, Y. (2017). Astrocytic modulation of neuronal excitability through $\mathrm{K}+$ spatial buffering. Neurosci. Biobehav. Rev. 77, 87-97. doi: 10.1016/j.neubiorev.2017.03.002

Bereshpolova, Y., Amitai, Y., Gusev, A. G., Stoelzel, C. R., and Swadlow, H. A. (2007). Dendritic backpropagation and the state of the awake neocortex. J. Neurosci. 27, 9392-9399. doi: 10.1523/jneurosci.2218-07.2007

Berger, T., Borgdorff, A., Crochet, S., Neubauer, F. B., Lefort, S., Fauvet, B., et al. (2007). Combined voltage and calcium epifluorescence imaging in vitro and in vivo reveals subthreshold and suprathreshold dynamics of mouse barrel cortex. J. Neurophysiol. 97, 3751-3762. doi: 10.1152/jn.01178.2006

Blomstrand, F., Khatibi, S., Muyderman, H., Hansson, E., Olsson, T., and Rönnbäck, L. (1999). 5-hydroxytryptamine and glutamate modulate velocity and extent of intercellular calcium signalling in hippocampal astroglial cells in primary cultures. Neuroscience $88,1241-1253$. doi: 10.1016/S0306-4522(98) 00351-350

Brooks, D. C. (1968). Waves associated with eye movement in the awake and sleeping cat. Electroencephalogr. Clin. Neurophysiol. 24, 532-541. doi: 10.1016/ 0013-4694(68)90042-90044

Buskila, Y., and Amitai, Y. (2010). Astrocytic iNOS-dependent enhancement of synaptic release in mouse neocortex. J. Neurophysiol. 103, 1322-1328. doi: 10.1152/jn.00676.2009

Buskila, Y., Farkash, S., Hershfinkel, M., and Amitai, Y. (2005). Rapid and reactive nitric oxide production by astrocytes in mouse neocortical slices. Glia 52, 169-176. doi: 10.1002/glia.20217

Buskila, Y., Morley, J. W., Tapson, J., and van Schaik, A. (2013). The adaptation of spike backpropagation delays in cortical neurons. Front. Cell. Neurosci. 7:1-9. doi: 10.3389/fncel.2013.00192

Buzsáki, G. (2002). Theta oscillations in the hippocampus. Neuron 33, 325-340. doi: 10.1016/S0896-6273(02)00586-X

Buzsaki, G. (2006). Rhythms of the Brain. Oxford: Oxford University Press.

Buzsáki, G., and Draguhn, A. (2004). Neuronal oscillations in cortical networks. Science 304, 1926-1929. doi: 10.1126/science.1099745

Cajal, S. R. Y. (1895). Algunas conjeturas sobre el mecanismo anatómico de la ideación, asociación y atención. Rev. Med. Cir. Pract. 36, 497-508.

Cajal, S. R. Y. (1897). Algo sobre la significación fisiológica de la neuroglia. Rev. Trimest. Microgr. 1, 3-47.

Carracedo, L. M., Kjeldsen, H., Cunnington, L., Jenkins, A., Schofield, I., Cunningham, M. O., et al. (2013). A neocortical delta rhythm facilitates reciprocal interlaminar interactions via nested theta rhythms. J. Neurosci. 33, 10750-10761. doi: 10.1523/jneurosci.0735-13.2013

Chai, H., Diaz-Castro, B., Shigetomi, E., Monte, E., Octeau, J. C., Yu, X., et al. (2017). Neural circuit-specialized astrocytes: transcriptomic, proteomic, morphological, and functional evidence. Neuron 95:531-549.e9. doi: 10.1016/j. neuron.2017.06.029

Connors, B. W., Gutnick, M. J., and Prince, D. A. (1982). Electrophysiological properties of neocortical neurons in vitro. J. Neurophysiol. 48, 1302-1320. doi: 10.1152/jn.1982.48.6.1302

Contreras, D., and Llinas, R. (2001). Voltage-sensitive dye imaging of neocortical spatiotemporal dynamics to afferent activation frequency. J. Neurosci. 21, 94039413. doi: 10.1523/jneurosci.21-23-09403.2001

Cornell-Bell, A. H., Finkbeiner, S. M., Cooper, M. S., and Smith, S. J. (1990). Glutamate induces calcium waves in cultured astrocytes: long-range glial signaling. Science 247, 470-473. doi: 10.1126/science.1967852

Cossart, R., Aronov, D., and Yuste, R. (2003). Attractor dynamics of network UP states in the neocortex. Nature 423, 283-288. doi: 10.1038/nature01614

Covelo, A., and Araque, A. (2016). Lateral regulation of synaptic transmission by astrocytes. Neuroscience 323, 62-66. doi: 10.1016/j.neuroscience.2015.02.036
Covelo, A., and Araque, A. (2018). Neuronal activity determines distinct gliotransmitter release from a single astrocyte. eLife 7:e32237. doi: 10.7554/ eLife.32237

Cunningham, M. O., Pervouchine, D. D., Racca, C., Kopell, N. J., Davies, C. H., Jones, R. S. G., et al. (2006). Neuronal metabolism governs cortical network response state. Proc. Natl. Acad. Sci. U.S.A. 103, 5597-5601. doi: 10.1073/pnas. 0600604103

D’Angelo, E., Nieus, T., Maffei, A., Armano, S., Rossi, P., Taglietti, V., et al. (2001). Theta-frequency bursting and resonance in cerebellar granule cells: experimental evidence and modeling of a slow $\mathrm{k}+$-dependent mechanism. J. Neurosci. 21, 759-770. doi: 10.1523/jneurosci.21-03-00759.2001

Dierig, S. (1994). Extending the neuron doctrine: carl ludwig schleich (18591922 ) and his reflections on neuroglia at the inception of the neural-network concept in 1894. Trends Neurosci. 17, 449-452. doi: 10.1016/0166-2236(94) 90129-90125

Ding, F., O’Donnell, J., Thrane, A. S., Zeppenfeld, D., Kang, H., Xie, L., et al. (2013). $\alpha 1$-Adrenergic receptors mediate coordinated Ca2+ signaling of cortical astrocytes in awake, behaving mice. Cell Calcium. 54, 387-394. doi: 10.1016/j. ceca.2013.09.001

Ding, F., O’Donnell, J., Xu, Q., Kang, N., Goldman, N., and Nedergaard, M. (2016). Changes in the composition of brain interstitial ions control the sleep-wake cycle. Science 352, 550-555. doi: 10.1126/science.aad4821

Dipoppa, M., and Gutkin, B. S. (2013). Flexible frequency control of cortical oscillations enables computations required for working memory. Proc. Natl. Acad. Sci. U.S.A. 110, 12828-12833. doi: 10.1073/pnas.1303270110

Do-Ha, D., Buskila, Y., and Ooi, L. (2018). Impairments in motor neurons, interneurons and astrocytes contribute to hyperexcitability in ALS: underlying mechanisms and paths to therapy. Mol. Neurobiol. 55, 1410-1418. doi: 10.1007/ s12035-017-0392-y

Eckart, C., Woźniak-Kwaśniewska, A., Herweg, N. A., Fuentemilla, L., and Bunzeck, N. (2016). Acetylcholine modulates human working memory and subsequent familiarity based recognition via alpha oscillations. Neuroimage 137, 61-69. doi: 10.1016/j.neuroimage.2016.05.049

Enoch, M. A., Shen, P. H., Ducci, F., Yuan, Q., Liu, J., White, K. V., et al. (2008). Common genetic origins for EEG, alcoholism and anxiety: the role of $\mathrm{CRH}-\mathrm{BP}$. PLoS One 3:e3620. doi: 10.1371/journal.pone.0003620

Fellin, T., Pascual, O., Gobbo, S., Pozzan, T., Haydon, P. G., and Carmignoto, G. (2004). Neuronal synchrony mediated by astrocytic glutamate through activation of extrasynaptic NMDA receptors. Neuron 43, 729-743. doi: 10.1016/ j.neuron.2004.08.011

Fiacco, T. A., Agulhon, C., Taves, S. R., Petravicz, J., Casper, K. B., Dong, X., et al. (2007). Selective stimulation of astrocyte calcium in situ does not affect neuronal excitatory synaptic activity. Neuron 54, 611-626. doi: 10.1016/j. neuron.2007.04.032

Fiacco, T. A., and McCarthy, K. D. (2018). Multiple lines of evidence indicate that gliotransmission does not occur under physiological conditions. J. Neurosci. 38, 3-13. doi: 10.1523/JNEUROSCI.0016-17.2017

Fields, R. D., and Stevens-Graham, B. (2002). Neuroscience: new insights into neuron-glia communication. Science 298, 556-562. doi: 10.1126/science.298. 5593.556

Filosa, J. A., Bonev, A. D., Straub, S. V., Meredith, A. L., Wilkerson, M. K., Aldrich, R. W., et al. (2006). Local potassium signaling couples neuronal activity to vasodilation in the brain. Nat. Neurosci. 9, 1397-1403. doi: 10.1038/nn1779

Fisahn, A., Pike, F. G., Buhl, E. H., and Paulsen, O. (1998). Cholinergic induction of network oscillations at $40 \mathrm{~Hz}$ in the hippocampus in vitro. Nature 394, 186-189. doi: $10.1038 / 28179$

Foley, J., Blutstein, T., Lee, S., Erneux, C., Halassa, M. M., and Haydon, P. (2017). Astrocytic IP3/Ca2+ signaling modulates theta rhythm and REM sleep. Front. Neural Circ. 11:3. doi: 10.3389/fncir.2017.00003

Freund, T. F., and Antal, M. (1988). GABA-containing neurons in the septum control inhibitory interneurons in the hippocampus. Nature 336, 170-173. doi: $10.1038 / 336170 \mathrm{a} 0$

Fries, P. (2005). A mechanism for cognitive dynamics: neuronal communication through neuronal coherence. Trends Cogn. Sci. 9, 474-480. doi: 10.1016/j.tics. 2005.08.011

Fries, P., Reynolds, J. H., Rorie, A. E., and Desimone, R. (2001). Modulation of oscillatory neuronal synchronization by selective visual attention. Science 291, 1560-1563. doi: 10.1126/science. 1055465 
Giaume, C., and Theis, M. (2010). Pharmacological and genetic approaches to study connexin-mediated channels in glial cells of the central nervous system. Brain Res. Rev. 63, 160-176. doi: 10.1016/j.brainresrev.2009.11.005

Haas, B., Schipke, C. G., Peters, O., Söhl, G., Willecke, K., and Kettenmann, H. (2006). Activity-dependent ATP-waves in the mouse neocortex are independent from astrocytic calcium waves. Cereb. Cortex 16, 237-246. doi: 10.1093/cercor/ bhi101

Hangya, B., Borhegyi, Z., Szilagyi, N., Freund, T. F., and Varga, V. (2009). GABAergic neurons of the medial septum lead the hippocampal network during theta activity. J. Neurosci. 29, 8094-8102. doi: 10.1523/jneurosci.566508.2009

Haydon, P. G., and Carmignoto, G. (2006). Astrocyte control of synaptic transmission and neurovascular coupling. Physiol. Rev. 86, 1009-1031. doi: 10.1152/physrev.00049.2005

He, B. J., Snyder, A. Z., Zempel, J. M., Smyth, M. D., and Raichle, M. E. (2008). Electrophysiological correlates of the brain's intrinsic large-scale functional architecture. Proc. Natl. Acad. Sci. U.S.A. 105, 16039-16044. doi: 10.1073/pnas. 0807010105

Henneberger, C., Papouin, T., Oliet, S. H. R., and Rusakov, D. A. (2010). Longterm potentiation depends on release of d-serine from astrocytes. Nature 463 , 232-236. doi: 10.1038/nature08673

Houades, V., Koulakoff, A., Ezan, P., Seif, I., and Giaume, C. (2008). Gap junctionmediated astrocytic networks in the mouse barrel cortex. J. Neurosci. 28, 5207-5217. doi: 10.1523/JNEUROSCI.5100-07.2008

Huber, R., Ghilardi, M. F., Massimini, M., and Tononi, G. (2004). Local sleep and learning. Nature 430, 78-81. doi: 10.1038/nature02663

Hughes, S. W., Lörincz, M., Cope, D. W., Blethyn, K. L., Kékesi, K. A., Parri, H. R., et al. (2004). Synchronized oscillations at $\alpha$ and $\theta$ frequencies in the lateral geniculate nucleus. Neuron 42, 253-268. doi: 10.1016/S0896-6273(04)001 91-196

Hughes, S. W., Lorincz, M. L., Blethyn, K., Kékesi, K. A., Juhász, G., Turmaine, M., et al. (2011). Thalamic gap junctions control local neuronal synchrony and influence macroscopic oscillation amplitude during EEG alpha rhythms. Front. Psychol. 2:193. doi: 10.3389/fpsyg.2011.00193

Hutcheon, B., and Yarom, Y. (2000). Resonance, oscillation and the intrinsic frequency preferences of neurons. Trends Neurosci. 23, 216-222. doi: 10.1016/ S0166-2236(00)01547-1542

Igelhorst, B. A., Niederkinkhaus, V., Karus, C., Lange, M. D., and Dietzel, I. D. (2015). Regulation of neuronal excitability by release of proteins from glial cells. Philos. Trans. R. Soc. B Biol. Sci. 370, 1-10. doi: 10.1098/rstb.2014.0194

Isomura, Y., Sirota, A., Zen, S., Montgomery, S., Mizuseki, K., Henze, D. A., et al. (2006). Integration and segregation of activity in entorhinal-hippocampal subregions by neocortical slow oscillations. Neuron 52, 871-882. doi: 10.1016/j. neuron.2006.10.023

Jedema, H. P. (2004). Corticotropin-releasing hormone directly activates noradrenergic neurons of the locus ceruleus recorded In Vitro. J. Neurosci. 24, 9703-9713. doi: 10.1523/JNEUROSCI.2830-04.2004

Jennings, A., Tyurikova, O., Bard, L., Zheng, K., Semyanov, A., Henneberger, C., et al. (2017). Dopamine elevates and lowers astroglial Ca2+ through distinct pathways depending on local synaptic circuitry. Glia 65, 447-459. doi: 10.1002/ glia. 23103

Jourdain, P., Bergersen, L. H., Bhaukaurally, K., Bezzi, P., Santello, M., Domercq, M., et al. (2007). Glutamate exocytosis from astrocytes controls synaptic strength. Nat. Neurosci. 10, 331-339. doi: 10.1038/nn1849

Jung, S., Pfeiffer, F., and Deitmer, J. W. (2000). Histamine-induced calcium entry in rat cerebellar astrocytes: evidence for capacitative and non-capacitative mechanisms. J. Physiol. 527, 549-561. doi: 10.1111/j.1469-7793.2000.00549.x

Kékesi, O., Liang, H., Münch, G., Morley, J. W., Gyengesi, E., and Buskila, Y. (2019). The differential impact of acute microglia activation on the excitability of cholinergic neurons in the mouse medial septum. Brain Struct. Funct. 224, 2297-2309. doi: 10.1007/s00429-019-01905-w

Kofuji, P., Ceelen, P., Zahs, K. R., Surbeck, L. W., Lester, H. A., and Newman, E. A. (2000). Genetic inactivation of an inwardly rectifying potassium channel (Kir4.1 Subunit) in mice: phenotypic impact in retina. J. Neurosci. 20, 5733-5740. doi: 10.1037/a0013262.Open

Kozachkov, L., and Michmizos, K. P. (2017). The Causal Role of Astrocytes in Slow-Wave Rhythmogenesis: A Computational Modelling Study. Piscataway, NJ: Rutgers University.
Lallouette, J., De Pittà, M., Ben-Jacob, E., and Berry, H. (2014). Sparse shortdistance connections enhance calcium wave propagation in a $3 \mathrm{D}$ model of astrocyte networks. Front. Comput. Neurosci. 8:45. doi: 10.3389/fncom.2014. 00045

Lalo, U., Palygin, O., Rasooli-Nejad, S., Andrew, J., Haydon, P. G., and Pankratov, Y. (2014). Exocytosis of ATP from astrocytes modulates phasic and tonic inhibition in the neocortex. PLoS Biol. 12:e1001747. doi: 10.1371/journal.pbio. 1001747

Larsen, B. R., and Macaulay, N. (2014). Kir4.1-mediated spatial buffering of KC: experimental challenges in determination of its temporal and quantitative contribution to KC clearance in the brain. Channels 8, 1-7.

Laudanski, J., Torben-Nielsen, B., Segev, I., and Shamma, S. (2014). Spatially distributed dendritic resonance selectively filters synaptic input. PLoS Comput. Biol. 10:1-10. doi: 10.1371/journal.pcbi.1003775

LeBeau, F. E. N., Towers, S. K., Traub, R. D., Whittington, M. A., and Buhl, E. H. (2002). Fast network oscillations induced by potassium transients in the rat hippocampus in vitro. J. Physiol. 542, 167-179. doi: 10.1113/jphysiol.2002. 015933

Lee, H. S., Ghetti, A., Pinto-Duarte, A., Wang, X., Dziewczapolski, G., Galimi, F., et al. (2014). Astrocytes contribute to gamma oscillations and recognition memory. Proc. Natl. Acad. Sci. U.S.A. 111, E3343-E3352. doi: 10.1073/pnas. 1410893111

Liljenström, H., and Hasselmo, M. (1993). Acetylcholine and cortical oscillatory dynamics. Comp. Neural. Syst. 523-530. doi: 10.1007/978-1-4615-3254-5_79

Ma, Z., Stork, T., Bergles, D. E., and Freeman, M. R. (2016). Neuromodulators signal through astrocytes to alter neural circuit activity and behavior. Nature 17, 428-432. doi: 10.1002/nbm.3369.Three

Magistretti, P. J. (2006). Neuron-glia metabolic coupling and plasticity. J. Exp. Biol. 209, 2304-2311. doi: 10.1242/jeb.02208

Mariotti, L., Losi, G., Lia, A., Melone, M., Chiavegato, A., Gómez-Gonzalo, M., et al. (2018). Interneuron-specific signaling evokes distinctive somatostatinmediated responses in adult cortical astrocytes. Nat. Commun. 9, doi: 10.1038/ s41467-017-02642-2646

Mariotti, L., Losi, G., Sessolo, M., Marcon, I., and Carmignoto, G. (2016). The inhibitory neurotransmitter GABA evokes long-lasting Ca2+ oscillations in cortical astrocytes. Glia 64, 363-373. doi: 10.1002/glia.22933

Maris, E., Fries, P., and van Ede, F. (2016). Diverse phase relations among neuronal rhythms and their potential function. Trends Neurosci. 39, 86-99. doi: 10.1016/ j.tins.2015.12.004

Matias, I., Morgado, J., and Gomes, F. C. A. (2019). Astrocyte heterogeneity: impact to brain aging and disease. Front. Aging Neurosci. 11:1-18. doi: 10.3389/fnagi. 2019.00059

McCormick, D. A. (1992). Neurotransmitter actions in the thalamus and cerebral cortex and their role in neuromodulation of thalamocortical activity. Prog. Neurobiol. 39, 337-388. doi: 10.1016/0301-0082(92)90012-90014

McCormick, D. A., and Pape, H. C. (1990). Properties of a hyperpolarizationactivated cation current and its role in rhythmic oscillation in thalamic relay neurones. J. Physiol. 431, 291-318. doi: 10.1113/jphysiol.1990.sp018331

Michelucci, A., Bithell, A., Burney, M. J., Johnston, C. E., Wong, K. Y., Teng, S. W., et al. (2016). The neurogenic potential of astrocytes is regulated by inflammatory signals. Mol. Neurobiol. 53, 3724-3739. doi: 10.1007/s12035-0159296-x

Muñoz, M. F., Puebla, M., and Figueroa, X. F. (2015). Control of the neurovascular coupling by nitric oxide-dependent regulation of astrocytic Ca2+ signaling. Front. Cell. Neurosci. 9:1-9. doi: 10.3389/fncel.2015.00059

Murthy, V. N., and Fetz, E. E. (2006). Coherent 25- to 35-Hz oscillations in the sensorimotor cortex of awake behaving monkeys. Proc. Natl. Acad. Sci. U.S.A. 89, 5670-5674. doi: 10.1073/pnas.89.12.5670

Navarrete, M., and Araque, A. (2014). The cajal school and the physiological role of astrocytes: a way of thinking. Front. Neuroanat. 8:33. doi: 10.3389/fnana.2014. 00033

Navarrete, M., Perea, G., de Sevilla, D. F., Gómez-Gonzalo, M., Núñez, A., Martín, E. D., et al. (2012). Astrocytes mediate in vivo cholinergic-induced synaptic plasticity. PLoS Biol. 10:e1001259. doi: 10.1371/journal.pbio.100 1259

Nedergaard, M., and Verkhratsky, A. (2012). Artifact versus reality-How astrocytes contribute to synaptic events. Glia 60, 1013-1023. doi: 10.1002/glia.2 2288 
Nett, W. J., Oloff, S. H., and McCarthy, K. D. (2017). Hippocampal astrocytes in situ exhibit calcium oscillations that occur independent of neuronal activity. J. Neurophysiol. 87, 528-537. doi: 10.1152/jn.00268.2001

Nir, Y., Staba, R. J., Andrillon, T., Vyazovskiy, V. V., Cirelli, C., Fried, I., et al. (2011). Regional slow waves and spindles in human sleep. Neuron 70, 153-169. doi: 10.1016/j.neuron.2011.02.043

Nunez, P. L. (1995). Neocortical Dynamics and Human EEG Rhythms. New York, NY: Oxford University Press.

Oberheim, N. A., Goldman, S. A., and Nedergaard, M. (2012). Heterogeneity of astrocytic form and function. Methods Mol. Biol. 814, 23-45. doi: 10.1007/9781-61779-452-450

Oikawa, H., Nakamichi, N., Kambe, Y., Ogura, M., and Yoneda, Y. (2005). An increase in intracellular free calcium ions by nicotinic acetylcholine receptors in a single cultured rat cortical astrocyte. J. Neurosci. Res. 79, 535-544. doi: 10.1002/jnr.20398

Pál, I., Kardos, J., Dobolyi, Á, and Héja, L. (2015). Appearance of fast astrocytic component in voltage-sensitive dye imaging of neural activity. Mol. Brain 8:35. doi: 10.1186/s13041-015-0127-129

Pannasch, U., and Rouach, N. (2013). Emerging role for astroglial networks in information processing: from synapse to behavior. Trends Neurosci. 36, 405-417. doi: 10.1016/j.tins.2013.04.004

Papouin, T., Henneberger, C., Rusakov, D. A., and Oliet, S. H. R. (2017). Astroglial versus neuronal d-serine: fact checking. Trends Neurosci. 40, 517-520. doi: 10.1016/j.tins.2017.05.007

Pascual, O., Casper, K. B., Kubera, C., Zhang, J., Revilla-Sanchez, R., Sul, J.-Y., et al. (2005). Astrocytic purinergic signaling coordinates synaptic networks. Science 310, 113-116. doi: 10.1126/science.1116916

Penttonen, M., and Buzsáki, G. (2003). Natural logarithmic relationship between brain oscillators. Thalamus Relat. Syst. 2, 145-152. doi: 10.1016/S1472-9288(03) 00007-4

Penttonen, M., Kamondi, A., Acsády, L., and Buzsáki, G. (1998). Gamma frequency oscillation in the hippocampus of the rat: intracellular analysis in vivo. Eur. J. Neurosci. 10, 718-728. doi: 10.1046/j.1460-9568.1998.00096.x

Perea, G., and Araque, A. (2007). Astrocytes potentiate transmitter release at single hippocampal synapses. Science 317, 1083-1086. doi: 10.1126/science.1144640

Petravicz, J., Fiacco, T. A., and McCarthy, K. D. (2008). Loss of IP3 receptordependent $\mathrm{Ca} 2+$ increases in hippocampal astrocytes does not affect baseline CA1 pyramidal neuron synaptic activity. J. Neurosci. 28, 4967-4973. doi: 10.1523/jneurosci.5572-07.2008

Peyrache, A., Battaglia, F. P., and Destexhe, A. (2011). Inhibition recruitment in prefrontal cortex during sleep spindles and gating of hippocampal inputs. Proc. Natl. Acad. Sci. U.S.A. 108, 17207-17212. doi: 10.1073/pnas.1103612108

Pike, F. G., Goddard, R. S., Suckling, J. M., Ganter, P., Kasthuri, N., and Paulsen, O. (2000). Distinct frequency preferences of different types of rat hippocampal neurones in response to oscillatory input currents. J. Physiol. 529, 205-213. doi: 10.1111/j.1469-7793.2000.00205.x

Pirttimaki, T. M., Sims, R. E., Saunders, G., Antonio, S. A., Codadu, N. K., and Parri, H. R. (2017). Astrocyte-mediated neuronal synchronization properties revealed by false gliotransmitter release. J. Neurosci. 37, 9859-9870. doi: 10.1523/jneurosci.2761-16.2017

Roopun, A. K., LeBeau, F. E. N., Rammell, J., Cunningham, M. O., Traub, R. D., and Whittington, M. A. (2010). Cholinergic neuromodulation controls directed temporal communication in neocortex in vitro. Front. Neural Circ. 4:8. doi: 10.3389/fncir.2010.00008

Roopun, A. K., Middleton, S. J., Cunningham, M. O., LeBeau, F. E. N., Bibbig, A., Whittington, M. A., et al. (2006). A beta2-frequency $(20-30 \mathrm{~Hz})$ oscillation in nonsynaptic networks of somatosensory cortex. Proc. Natl. Acad. Sci. U.S.A. 103, 15646-15650. doi: 10.1073/pnas.0607443103

Sanchez-Vives, M. V., and McCormick, D. A. (2000). Cellular and network mechanisms of rhythmic recurrent activity in neocortex. Nat. Neurosci. 3, 1027-1034. doi: 10.1038/79848

Sardinha, V. M., Guerra-Gomes, S., Caetano, I., Tavares, G., Martins, M., Reis, J. S., et al. (2017). Astrocytic signaling supports hippocampal-prefrontal theta synchronization and cognitive function. Glia 65, 1944-1960. doi: 10.1002/glia. 23205

Savtchouk, I., and Volterra, A. (2018). Gliotransmission: beyond black-and-white. J. Neurosci. 38, 14-25. doi: 10.1523/JNEUROSCI.0017-17.2017
Schaul, N. (1998). The fundamental neural mechanisms of electroencephalography. Electroencephalogr. Clin. Neurophysiol. 106, 101-107. doi: 10.1016/S0013-4694(97)00111-119

Schleich, C. L. (1894). Schmerzlose Operationen. Berlin: Springer.

Shigetomi, E., Kracun, S., Sofroniew, M. V., and Khakh, B. S. (2010). A genetically targeted optical sensor to monitor calcium signals in astrocyte processes. Nat. Neurosci. 13, 759-766. doi: 10.1038/nn.2557

Singer, W. (1993). Synchronization of cortical activity and its putative role in information processing and learning. Annu. Rev. Physiol. 55, 349-374. doi: 10.1146/annurev.physiol.55.1.349

Skaggs, W. E., McNaughton, B. L., Permenter, M., Archibeque, M., Vogt, J., Amaral, D. G., et al. (2007). EEG Sharp waves and sparse ensemble unit activity in the macaque hippocampus. J. Neurophysiol. 98, 898-910. doi: 10.1152/jn.00401. 2007

Soltesz, I., Lightowler, S., Leresche, N., Jassik-Gerschenfeld, D., Pollard, C. E., and Crunelli, V. (1991). Two inward currents and the transformation of lowfrequency oscillations of rat and cat thalamocortical cells. J. Physiol. 441, 175-197. doi: 10.1113/jphysiol.1991.sp018745

Steriade, M. (2006). Grouping of brain rhythms in corticothalamic systems. Neuroscience 137, 1087-1106. doi: 10.1016/j.neuroscience.2005.10.029

Steriade, M., McCormick, D. A., and Sejnowski, T. J. (1993). Thalamocortical oscillations in the sleeping and aroused brain. Science 262, 679-685. doi: $10.1126 /$ science. 8235588

Steriade, M., Nunez, A., and Amzica, F. (2018). A novel slow ( $<1 \mathrm{~Hz})$ oscillation of neocortical neurons in vivo: depolarizing and hyperpolarizing components. J. Neurosci. 13, 3252-3265. doi: 10.1523/jneurosci.13-08-03252.1993

Stobart, J. L., Ferrari, K. D., Barrett, M. J. P., Glück, C., Stobart, M. J., Zuend, M., et al. (2018). Cortical circuit activity evokes rapid astrocyte calcium signals on a similar timescale to neurons. Neuron 98:726-735.e4. doi: 10.1016/j.neuron. 2018.03.050

Suadicani, S. O. (2006). P2X7 receptors mediate atp release and amplification of astrocytic intercellular Ca2+ signaling. J. Neurosci. 26, 1378-1385. doi: 10.1523/ jneurosci.3902-05.2006

Suzuki, A., Stern, S. A., Bozdagi, O., Huntley, G. W., Walker, R. H., Magistretti, P. J., et al. (2011). Astrocyte-neuron lactate transport is required for long-term memory formation. Cell 144, 810-823. doi: 10.1016/j.cell.2011.02.018

Takata, N., and Hirase, H. (2008). Cortical layer 1 and layer 2/3 astrocytes exhibit distinct calcium dynamics in vivo. PLoS One 3:e2525. doi: 10.1371/journal.pone. 0002525

Tallon-Baudry, C., Mandon, S., Freiwald, W. A., and Kreiter, A. K. (2004). Oscillatory synchrony in the monkey temporal lobe correlates with performance in a visual short-term memory task. Cereb. Cortex 14, 713-720. doi: 10.1093/cercor/bhh031

Tapson, J. C., Cohen, G. K., Afshar, S., Stiefel, K. M., Buskila, Y., Wang, R. M., et al. (2013). Synthesis of neural networks for spatio-temporal spike pattern recognition and processing. Front. Neurosci. 7:153. doi: 10.3389/fnins.2013. 00153

Tohidi, V., and Nadim, F. (2009). Membrane resonance in bursting pacemaker neurons of an oscillatory network is correlated with network frequency. J. Neurosci. 29, 6427-6435. doi: 10.1523/JNEUROSCI.0545-09.2009

Traub, R. D., Whittington, M. A., Buhl, E. H., LeBeau, F. E. N., Bibbig, A., Boyd, S., et al. (2001). A possible role for gap junctions in generation of very fast EEG oscillations preceding the onset of, and perhaps initiating, seizures. Epilepsia 42, 153-170. doi: 10.1046/j.1528-1157.2001.26900.x

Ullian, E. M., Sapperstein, S. K., Christopherson, K. S., and Barres, B. A. (2001). Control of synapse number by glia. Science 291, 657-661. doi: 10.1126/science. 291.5504.657

Ushimaru, M., Ueta, Y., and Kawaguchi, Y. (2012). Differentiated participation of thalamocortical subnetworks in slow/spindle waves and desynchronization. J. Neurosci. 32, 1730-1746. doi: 10.1523/jneurosci.4883-11.2012

Verkhratsky, A., and Nedergaard, M. (2018). Physiology of astroglia. Physiol. Rev. 98, 239-389. doi: 10.1152/physrev.00042.2016

Wang, F., Nathan, S. A., Xu, Q., Fujita, T., Baba, A., Matsuda, T., et al. (2012). Astrocytes modulate neural network activity by $\mathrm{Ca} 2+$ dependent uptake of extracellular K+. Sci. Signal. 5, 1-15. doi: 10.1126/scisignal.2002334

Wang, F., Smith, N. A., Xu, Q., Goldman, S., Peng, W., Huang, J. H., et al. (2013). Photolysis of caged Ca2+ but not receptor-mediated $\mathrm{Ca} 2+$ signaling 
triggers astrocytic glutamate release. J. Neurosci. 33, 17404-17412. doi: 10.1523/ jneurosci.2178-13.2013

Watson, B. O. (2015). Sleep, memory \& brain rhythms. Daedalus 144, 67-82. doi: 10.1162/DAED-a-00318

Whittington, M. A., and Traub, R. D. (2003). Interneuron diversity series: inhibitory interneurons and network oscillations in vitro. Trends Neurosci. 26, 676-682. doi: 10.1016/j.tins.2003.09.016

Whittington, M. A., Traub, R. D., and Jefferys, J. G. R. (1995). Synchronized oscillations in interneuron networks driven by metabotropic glutamate receptor activation. Nature 373, 612-615. doi: 10.1038/3736 $12 \mathrm{a} 0$

Wolosker, H., Balu, D. T., and Coyle, J. T. (2016). The rise and fall of the d-serine-mediated gliotransmission hypothesis. Trends Neurosci. 39, 712-721. doi: 10.1016/j.tins.2016.09.007

Yue, B. W., and Huguenard, J. R. (2001). The role of H-current in regulating strength and frequency of thalamic network oscillations.
Thalamus Relat Syst. 1, 95-103. doi: 10.1016/s1472-9288(01)00 009-7

Zur Nieden, R., and Deitmer, J. W. (2006). The role of metabotropic glutamate receptors for the generation of calcium oscillations in rat hippocampal astrocytes in situ. Cereb. Cortex 16, 676-687. doi: 10.1093/cercor/bhj013

Conflict of Interest: The authors declare that the research was conducted in the absence of any commercial or financial relationships that could be construed as a potential conflict of interest.

Copyright (C) 2019 Buskila, Bellot-Saez and Morley. This is an open-access article distributed under the terms of the Creative Commons Attribution License (CC BY). The use, distribution or reproduction in other forums is permitted, provided the original author(s) and the copyright owner(s) are credited and that the original publication in this journal is cited, in accordance with accepted academic practice. No use, distribution or reproduction is permitted which does not comply with these terms. 